\title{
A Study on the Standardization of Micro-blog Language in Local Metropolis Newspapers
}

\author{
Chen $\mathrm{Li}^{1, \mathrm{a}}$, Li Wang ${ }^{1, \mathrm{~b}^{*}}$ \\ ${ }^{1}$ University of Electronic Science and Technology of China, Chengdu, Sichuan, P.R.China \\ ${ }^{2}$ University of Electronic Science and Technology of China, Chengdu, Sichuan, P.R.China \\ a649098611@qq.com, bs_peacock@163.com \\ *Li Wang
}

Keywords: Local Metropolis Newspapers, Micro-blog, Standardization Language

\begin{abstract}
Since the beginning of the 21st century, in the face of the crisis brought by the rapid development of new media, local metropolis newspapers set off a wave of micro-blogging, which is an important way for traditional media to seek transformation. In this paper, choosing Chengdu Economic Daily and Chengdu Evening Post of Chengdu Media Group as the research object, we analyze the contents of these two media released on Sina Micro-blog and explore the standardization of micro-blog language. The study found that, in the micro-blogs of local metropolis newspapers, the use of ambiguous vocabularies and non-standardized news vocabularies concerning the themes of leisure life are frequent, while the use of network buzzwords, oral, emoticons, punctuation is very unique.
\end{abstract}

\section{Introduction}

Micro-blog is a popular social network platform that shares short real-time information through a attention mechanism, updates information with about 140 words and enables instant sharing. ${ }^{[1]}$ The micro-blog language is a unique network language that is disseminated over the network and is published timely. "Generalized network language" refers to the terms and expressions that related to the field of network, computer and so on; "narrow network language" refers to the symbol systems in the virtual language community that used to exchange, transmit information, including verbal systems and non-verbal systems such as expressions, sounds, images, and so on. ${ }^{[2]}$ Obviously, the micro-blog language discussed in this article is a kind of the network language, while the study of pictures, audios and videos are not included in this article.

\section{Statement of Problem}

In 9 cases of typical media ethical issues, published by the "Annual Media Ethics Research Group" $^{(1)}$, there are 4 cases of media ethics problems caused by the non-standardized vocabularies. Nowadays, with the diversification of social culture and the development of individuality, non-standardized vocabularies often appears in reports of major new medias, including local micro-blog medias. As the representative of the local metropolis newspapers in the southwest area, what is the current situation of micro-blog language of the Chengdu Economic Daily and Chengdu Evening Post? Did it use improper vocabularies? In addition, whether there is a learning experience of usage of vocabularies available to other local metropolis newspapers? These are the main concerns of this paper.

Through the research of CNKI, this article found that the current situation of Chinese academic research towards "Micro-blog Language" is very well, which could be summed up mainly into the following categories. The first category is the research of current situation of the punctuation and rhetorical use in micro-blog language. For example, Cheng Aixia and Li Quanxing analyzed those

(1) Research Report of The Media Ethics Problems in 2016, Journalism, 2017 (2) 
popular Sina micro-blogs, concluding that the use of punctuation in micro-blog language derived a lot of new usage. Besides the normal uses, the de-use and variation are the current three trends. ${ }^{[3]}$ The second category of research is to analyze the characteristics and effects of micro-blog language from the perspective of linguistics. Such as Qu Zhuanyi pointed out that the simplification, generalization, fragmentation and personalization of language are main features of the current micro-blog language. ${ }^{[4]}$ The third category is the study of micro-blog language from the perspective of semiotics. Such as Wang Youyan interpreted of "ASCII emoticons", "emoticons", "Taobao styles" and other micro-blog language from the cognitive function, communication function of symbols. And she further suggested that some of the symbols, vocabularies and grammars in the micro-blog language which are contrary to the modern Chinese language will die due to the lack of general agreement of society. ${ }^{[5]}$ The fourth category is to explore the composition of micro-blog language. Such as Liu Yuandong analyzed the composition of homophonic words, onomatopoeic words and regional dialects from the phonological level,and further analyzed the composition of both tradition written words and new internet-words in micro-blog language from the level of vocabulary. ${ }^{[6]}$ The fifth category is a reflection of micro-blog language.

Through the above research, this paper found that academic community rarely use quantitative methods to study micro-blog language, and pay less attention towards its problems and development. In addition, in CNKI there is no paper research the current situation of the standardization of micro-blog language in local metropolis newspapers.

\section{Research Methods}

This study mainly uses the Content Analysis Method to analyze the information released in Sina Micro-blog by Chengdu Economic Daily and Chengdu Evening Post.

\subsection{The Selection of Samples}

\subsubsection{The Selection of Target Medias}

Until April 2017, fans of "@Chengdu Economic Daily" which daily releases of about 40 messages have reached 8.77 million; fans of "@Chengdu Evening Post" which daily releases of about 35 messages have reached 5.52 million. Such a huge consuming scale highlights the influence of the two local medias. In addition, micro-blog medias can find specific news information based on the search and time axis, which to some extent to achieve the purposes of quick-find and long retention of information. This paper chooses these two medias as the research object based on these two points.

\subsubsection{Design and Extract Those Samples}

The study selected contents, from January 1st to April 1st in 2017, published by "@Chengdu Economic Daily" and "@Chengdu Evening Post", these two Sina Micro-blog, as the sample. This article received news reports from these two media, 162 messages from "@Chengdu Economic Daily" and 135 messages from "@Chengdu Evening Post", of all which constitute the full sample of this study.

\subsection{The Construction and Description of the Category}

After reading and studying the samples, this article regards each news as a coding unit, and designs the coding table from the following four aspects: the degree of rigorousness, the subject of the reports, the emotional tendency of the discourse and the diversity of form.

\subsubsection{The Degree of Rigorousness}

First, the published texts, vocabularies, phenomenon of non-standardized grammars is to be monitored: whether the types, idioms, synonyms, network language, foreign words are standardized, whether there is a label language, whether published texts which are clearly prohibited by laws and regulations and obvious violated social orders and so on. And concerning the facts that lack of evidence, whether there is a clear statement in the title, key words involved are "diao si or loser", 
"fu er dai or rich second generation", "yi si or may be", "wang bao or exposure online" and so on.

\subsubsection{The Theme of Reports}

The subject of news coverage is the main content of the report. According to the preliminary analysis of samples, this category is further divided into three parts, namely, News \& Information, Life \& Leisure, Comments of People's livelihood.

\subsubsection{The Emotional Tendency of the Discourse}

According to the research needs, this part mainly includes three kinds of situations, the use of network language, the use of expression symbols, the use of spoken language, key words involved are "xiao cry or face with tears of joy", "chao ji meng or super cute", "ba shi or super cool" and so on.

\subsubsection{The Diversity of Form}

This part analyzes the use of contrast and comparison in sentences; the use of metaphor, anthropomorphic and other types of rhetoric; the use of numbers, colors, shapes, punctuation and other elements, to explore of the effect brought by these means of communications.

\subsection{The Reliability of Coders}

In order to ensure the scientificity and accuracy of the Content Analysis Method, there are two coders involved in the coding work. The reliability test, using Cohen's Kappa index formula, in the case of exclusion of random factors, the reliability value was of 0.85 , which was greater than the minimum requirements of the test 0.7 . So the result of this code would be scientific and reliable.

\section{The Discovery of This Study}

\subsection{The Overall Expression Is Related Rigorous, But the Use of Ambiguous Vocabularies Are Frequent.}

Table 1. ${ }^{1}$

The Statistics Table of The Use of Ambiguous Vocabularies in Micro-blogs of Local Metropolis Newspapers in 2017

Unit: Cases

\begin{tabular}{|l|c|c|c|c|}
\hline & may be & net-spread & it is said & it is understood \\
\hline "@Chengdu Economic Daily" & 36 & 10 & 44 & 30 \\
\hline "@Chengdu Evening Post" & 12 & 4 & 38 & 5 \\
\hline
\end{tabular}

After analyzing the collected samples, it was found that, in this 297 report, there was no published content that are explicitly prohibited by laws and regulations and obviously violates social order, and there was no typos also, but the use of network language is more common, which accounts for $14 \%$ of the total number of samples, mainly in the category of "Life \& Leisure". In all these samples, there were 23 cases of non-standardization, accounting for $7.7 \%$ of the total samples, including 10 cases of using ambiguous words, 6 cases of insufficient sentence composition, 3 cases of vulgar words, 2 cases of exaggerated titles, 1 case of non-standardized proverbs, 1 case of ambiguity. Specific reports are listed below. Such as "Ball-Hurting! \#One Man Tied 7 Cars On His Testis\# And Pulled Cars 8 Meters." ("@Chengdu Economic Daily" April 1st); "It Is Said That The Relevant Agencies Have Organized The Second Mental Identification Towards The Guilty Driver." (@Chengdu Economic Daily" on March 1st); "Two Small UAVs Were Artificially Installed Artillery That May Be Firecrackers And Attacked Each Other For Fun." ("@Chengdu Economic Daily "February 1st). Concerning those facts that lack of evidence, "@Chengdu Economic Daily" and "@Chengdu Evening Post", these two micro-blogs were using more ambiguous words, such as

(1) The data ended on April $18^{\text {th }}, 2017$ 
"may be", "net-spread", "It is said", "it is understood" and so on. Through the investigation of all the contents published in the first four months in 2017, 179 cases were found, including 48 cases of "may be", 14 cases of "net-spread", 82 cases of "it is said", 35 cases of "it is understood" (see Table 1).

\subsection{Vocabularies Used in The Theme of Life \& Leisure Were More Non-standardized Than Others.}

After analyzing these collected samples, it was found that, among the 297 samples, there were 98 cases under the category of News \& Information, accounting for 33\% of the total number of reports; there were 164 cases under the category of Life \& Leisure, accounting for $55 \%$ of the total number of reports; there were 28 cases under the category of Comments of People's livelihood, accounting for $9 \%$ of the total number of reports; and there were 7 other cases, accounting for $2 \%$ of the total numbers of reports (See Table 2). It can be seen from the data, micro-blogs of metropolis newspaper much more inclined to publish news under the category of Life \& Leisure. Its language style is lively and its expression is diversified and popularized. However, in the 23 cases of non-standardized vocabularies, there are 14 cases under the category of Life \& Leisure, accounting for 60.8\%. For example, there are cases which words are not standardized: "The Guilty Driver, Please Surrender Immediately" ("@Chengdu Evening Post" January 1st),"There Were Mistakes In Drama Show, While Two Masters Turned It Into Highlights."("@Chengdu Evening Post" February 1st); using of vulgar words, such as "Zhang Ziyi Cursed Netizens With sbtd :obij:" ("@Chengdu Economic Daily" February 1st).These words, in the text and the expression of statements, has a greater randomness and are not formal concerning the standardization of languages.

\section{Table 2. ${ }^{(1)}$}

The Statistics Table of The Use of Non-Standardized Vocabularies in Local Metropolis Newspapers in 2017

Unit: Case

\begin{tabular}{|l|c|c|c|c|}
\hline & $\begin{array}{c}\text { News \& } \\
\text { Information }\end{array}$ & $\begin{array}{c}\text { Life \& } \\
\text { Leisure }\end{array}$ & $\begin{array}{c}\text { Comments } \\
\text { of People's } \\
\text { livelihood }\end{array}$ & Other Sections \\
\hline "@Chengdu Economic Daily" & 32 & 86 & 13 & 4 \\
\hline "@Chengdu Evening Post" & 66 & 78 & 15 & 3 \\
\hline Problems & 5 & 16 & 2 & 0 \\
\hline
\end{tabular}

\subsection{The Use of Network Buzzwords and Spoken Language Is Common and the Emotional Tendency of Discourse Is Strong.}

As a form of new media, micro-blogs of local metropolis newspapers changed the rigorous and professional styles of paper media and use network buzzwords extensively. Such as: "People's Daily Recommended RAP Animation: My NPC \&CPPCC, My Council." (@Chengdu Evening Post March 1st); "The Spring Is Coming: Biu Biu Biu, Your Brothers Are Sending Messages." (@Chengdu Evening Post April 1st),"Arctic Foxes Are Sad: You Are Samoyed! Your Whole Family Are Samoyed!" ("@Chengdu Evening Post" April 1st) and so on. After combing the entire sample, this article also found that the use of spoken language is very common. "@Chengdu Economic Daily" accounted for 22.2\% and "@Chengdu Evening Post" accounted for 30.00\% (see Table 3). Such as: "Easy To Learn: Home-Made Pickle-Fish Is Super Cool."(@Chengdu Economic Daily January 1st); "Fuck Off. Just Get Off. Why You Not Just Get Off." (@Chengdu Economic Daily January 1st), "Old Lady Started Stall Besides Street While City Inspectors Helped Her." (@Chengdu Evening Post January 1st),"A Lady Shouting At A Naughty Child Was Beat By His Parents."("@Chengdu Evening Post" March 1st). The use of network buzzwords and verbal expressions, with the characteristics of freshness and populism, usually adopts irony, ridicule, exaggeration and populist expressions to

(1) The data ended on April $18^{\text {th }}, 2017$ 
report and comment on events or peoples, and the contents conveyed are thoughtful, active and critical.

Table $3^{(1)}$. The Statistics Table of The Use of Network and Spoken Expressions in Micro-blogs of Metropolis Newspapers

\begin{tabular}{|c|c|c|c|c|c|}
\hline & $\begin{array}{c}\text { The Number } \\
\text { of Whole } \\
\text { Messages of } \\
\text { Sample }\end{array}$ & $\begin{array}{c}\text { The Number of } \\
\text { Messages Using } \\
\text { Network } \\
\text { Language } \\
\text { Published In } \\
\text { Micro-blogs }\end{array}$ & $\begin{array}{c}\text { The Percentage } \\
\text { of The Using } \\
\text { of Network } \\
\text { Language (\%) }\end{array}$ & $\begin{array}{c}\text { The Number of } \\
\text { Using Spoken } \\
\text { Language } \\
\text { Published In } \\
\text { Micro-blogs }\end{array}$ & $\begin{array}{c}\text { The Percentage of } \\
\text { The Using of } \\
\text { Spoken Language } \\
\text { (\%) }\end{array}$ \\
\hline $\begin{array}{c}\text { "@Chengdu } \\
\text { Economic Daily" }\end{array}$ & 162 & 41 & $25.30 \%$ & 36 & $22.20 \%$ \\
\hline $\begin{array}{c}\text { "@Chengdu } \\
\text { Evening Post" }\end{array}$ & 135 & 33 & $24.40 \%$ & 31 & $30.00 \%$ \\
\hline
\end{tabular}

4.4. Through the Special Use of Emoticons and Punctuation, Micro-Blog Messages Portrayed the Micro-Blog Language With An Impression of Conciseness and Freestyle.

Concerning the micro-blog language in the form of performance, after the analysis of the entire sample, this paper found that the use of emoticons is very common: "@Chengdu Economic Daily" accounted for 80.8\%; while "@Chengdu Evening Post" accounted for 63.7\%. Such as: "Chinese Zhang's Clay Figures Making Clay Figurines In This Way. Excellent Craftsman Excellent Crafts-Spirit! ("@Chengdu Economic Daily" January 1st),"The Charisma Is Too Strong ! This Fit Is Awesome. "("@Chengdu Economic Daily" January 1st), "A Man In Zhaozhou Daqing Was Beating His Sleeping Daughter! So Awful! $82="$ ("@Chengdu Evening Post"April 1st). A variety of expressions and emoticons together conveyed feelings and ideas, which is conducive not only to show the media's position and guide the audience, but also to meet its performance style of simplicity and freestyle.

Micro-blog medias of metropolis newspaper in the use of punctuation are mainly three ways, namely, stacking, combination and pause. Such as: "The Worst Video of Jack Zhou! Hold On! Don't Laugh! Hah Hah Hah! Feeling Pity For Him." ("@Chengdu Evening Post" February 1st).Title with a number of exclamation points, question marks to express the strong tone and strong feelings, such as doubt, suspect, distrust, or strong anger, dissatisfaction, or irony, criticism and condemnation. The more the number of stacks, the stronger the tone and emotion. Such as: "Arrest The Murder! The Guilty Driver Please Surrender Immediately! Notice: No Driving After Drinking! Please Slow Down When You Encounter Sanitation Workers!"("@Chengdu Economic Daily" January 1st),"What Kind of Parents You Are?! Taking Baby To Hospital In Afternoon, And Dropping Him At Night?!"("@Chengdu Economic Daily" February 1st). This combination of multiple punctuation marks are mainly the combination of question marks and exclamation points. Generally, question mark, former, exclamation mark, latter, expressing a strong feeling. And in some points in the sentences where should not be stopped would use the exclamation points which has a new form of novelty and highlights, and is the center of semantic expression. Such a sentence shall be read in prolonged sound with slow pace, or increase reading volume, in order to express shock, surprise, exclamation or joy and so on. Classic example is: "Sister Shang Is Going To Send Red Envelopes! RED! ENVEIOPES!Come And Have A Fortune!" ("@Chengdu Economic Daily" January 1st)

\section{Conclusion}

Micro-blog, as the representative of the new media, compared to traditional paper media, due to its lack of effective means of control, often become the "Disaster Area" of non-standardized language. This study draws the following conclusions:

First, micro-blogs in local metropolis newspapers are accompanied by entertainment. In the

(1) The data ended on April $18^{\text {th }}, 2017$ 
sample, the daily push is around the 3-9 messages, an average of 5 messages per day. Anything that relates to entertainment news has a high degree of flexibility and diversity in language use and presentation elements. Second, the new medias of metropolis newspapers use the network platform to pursue exclusivity and timeliness, which reduces the accuracy and rigorousness of the news and also increases the use of ambiguous words in local-metropolis newspapers. Again, micro-blogs in local metropolis newspapers serves the local media. In the dissemination of content, they would focus on the local news and choose local colloquial expressions.

New media is an important field of transformation of paper medias in recent years, and micro-blog media continue to expand the authority and influence of it with its simple language, strong platform interaction and multi-element means of communication. In the "Ethics Discussion Under The Era of Network", organized by the "Chinese Social Science" magazine, scholars thought there are three internal dimensions in the dissemination of morality under the era of network, namely, standardized ethics, technical ethics and virtue ethics. ${ }^{[7]}$ The media ethic construction, under the context of new media, also continues to present rich and realistic questions for our research. And these issues need to be maintained and standardized, from the perspectives of country, society, media, media workers, even the audience and other levels.

\section{References}

[1] Zeng Ti, On the Language Style of Local Party Newspaper, J. Chinese Publishing House. 2014-11-23.

[2] Liu Yuandong, On the Components and Influence of Micro-blog Language, J. Shang. 2016-04-06.

[3] Chen Aixia, Li Quanxin, An Analysis of the Use of Punctuation Marks in Micro-blog Language - A Case Study of Popular Sina Micro-blogs, J. Journal of West Anhui University. 2015-12-15.

[4] Qu Zhuanyi, The Characteristics of Micro-blog Language from the Perspective of Sociolinguistics, J. Overseas English. 2012-02-08.

[5] Wang Youran, The semiotic study of microblogging language, J. Journal of Yangtze University (Social Science Edition). 2014-02-15.

[6] Liu Yuandong, On the Components and Influence of Micro-blog Language, J. Shang. 2016-04-06.

[7] Resource are gained from the network of Chinese social science http://www.cssn.cn/zx/201606/t20160602_3053555.shtml. 